Journal of Qualitative Criminal Justice \& Criminology

\title{
Becoming a Hacker: \\ Demographic \\ Characteristics and \\ Developmental Factors
}

Kevin F. Steinmetz ${ }^{1}$

${ }^{1}$ Kansas State University

Published on: Aug 16, 2020

License: Creative Commons Attribution 4.0 International License (CC-BY 4.0). 


\begin{abstract}
Hackers are not defined by any single act; they go through a process of development. Building from previous research and through ethnographic interviews and participant observation, the current analysis examines characteristics which may influence an individual's development as a hacker. General demographic characteristics are analyzed, the participants' school experiences are discussed, and perceived levels of parental support and influence are defined. Finally, descriptions of first exposures to technology, the concept of hacking, and the hacking community are presented. The study concludes with theoretical implications and suggestions for future research.
\end{abstract}

\title{
Introduction
}

As a concept, hacking is a contested issue. For some, the term is synonymous with computer intrusions and other forms of technological malfeasance (Wall, 2007). Others consider hacking to be broader, to include activities like open-source software programming, and hardware hacking, among actions (Coleman, 2012; Coleman, 2013; Söderberg, 2008). Some consider hacking along ethical divisions, most notably described as black hats and white hats or hackers versus crackers (Holt, 2009; Taylor, 1999). What has become clear about hacking in the decades since its inception among technology students at MIT in the 1950s and 1960s (Levy, 1986) is that it serves as a lightning rod that attracts cultural conflict and public concern.

Part of the disagreement over hacking stems from media and social construction (Halbert, 1997; Hollinger, 1991; Skibell, 2002; Taylor, 1999; Yar, 2013). Since hackers first emerged in popular culture in movies like War Games in 1986 and hackers in 1995, the image of the hacker has been shrouded in fear and fascination (Hollinger, 1991; Skibell, 2002). This allure has been reinforced by various hacker controversies and events in recent times. For instance, approximately one hundred individuals were arrested recently in a crackdown targeting alleged hackers associated with the Blackshades malware (Perez \& Prokupecz, 2014). Hackers have taken a position in the international spotlight with the actions of hacktivist (a term combining hacker and activist) groups like Anonymous and LulzSec who have engaged in web site defacements, distributed denial of service attacks, and created security breaches of various government, security, or corporate organizations (Olson, 2012). Additionally, in 2012 President Barak Obama pointed to hackers as a potential major national security issue. Such events and their subsequent portrayals have led to socially-constructed images which shroud hackers in mythology (Halbert, 1997; Hollinger, 1991; Skibell, 2002; Taylor, 1999; Yar, 2013).

Such constructions have led to the perception that hackers are "young men whose pathological addiction to the internet leads to elaborate deceptions, obsessive quests for knowledge, and bold tournaments of sinister computer break-ins" (Coleman \& Golub, 2008, p. 256). Such perceptions often 
cast hackers as demonized figures lurking in the netherworld, ready to wreak havoc over the wires. In other words, the hacker becomes a figment in the cultural imagination largely divorced from personal history, context, and humanity.

Breaking away from such myopic portrayals, hacking is viewed here as a kind of "late-modern transgressive technological craft" (Steinmetz, 2014, p. 6. Hacking is thus recognized as a "process of becoming" rather than a state one embodies (Steinmetz, 2014, p. 2). Hackers do not emerge from a void, mouse-in-hand with technical knowledge and skill accumulated. Rather, hacking is about development. This process, for most, begins early and is affected by various life events, relationships, and institutions. Since hackers are largely made rather than born, this study builds on previous research examining hacker maturation (Bachmann, 2010; Holt, 2009; Holt, 2010a; Schell, Dodge, \& Moutsatsos, 2002; Schell \& Holt, 2010) by focusing on developmental circumstances and demographical characteristics through ethnographic field research (including participant observation and interview data) of a hacker group pseudonymously referred to as Union Hack. Such research could provide a more accurate depiction of hackers than commonly seen in popular culture and public discourse. While previous analyses have made strides in these areas (e.g., Bachmann, 2010; Coleman, 2013; Holt, 2009; Holt, 2010a; Schell et al., 2002; Schell \& Holt, 2010; Taylor, 1999; Söderberg, 2008), more research is needed in light of the pervasiveness of hacker mythologization and its potential consequences including knee-jerk policy reactions, disproportionate sentencing, and public fear. In the age of high technology, hackers are prominently demonized even though they are also involved in substantive advances in technological development (Coleman, 2013; Thomas, 2002). Changing misperceptions as well as probing features conducive to becoming a hacker appears to be a vital step toward understanding the nuanced role hackers hold in late modernity.

Before discussing the results of this analysis, the literature is reviewed with particular attention paid to previous studies examining hacker backgrounds and development. A short discussion of the ethnographic method used in this study is then provided. Finally, the results are presented which include (1) general background characteristics; (2) educational experiences; (3) parental support and influence; and (4) first exposures to technology, the idea of hacking, and the hacking community. The study concludes with an overview of the findings and a discussion of implications.

\section{Literature Review}

As networked technologies become more pervasive in late modern society, corresponding concerns arise over how such systems might be manipulated or compromised for nefarious purposes. As Yar (2013) stated, "Yet awareness of, and enthusiasm for, these changes have been tempered by fears that the Internet brings with it new threats and dangers to our well-being and security" (p. 3). Technocrime has thus become a hot topic in popular culture, political discourse, and in scholarship and can be understood "not so much [as] a single, distinctive kind of criminal activity, but more ... a diverse range 
of illegal and illicit activities that share in common the unique electronic environment ('cyberspace') in which they take place [italics in original]" (Yar, 2013, p. 5). - Despite this digital context, "many of the basic crime ideas" described as technocrime "remain familiar" (Wall, 2007, p. 2). Even with this familiarity, law enforcement struggles to keep up with technocriminals and deviants as technology shifts and spreads under their feet (Nhan \& Huey, 2013). To make matters worse, social construction has heavily skewed political and popular perceptions of technocriminals (Yar, 2013). Over time, these distortions have generated an archetypal technocriminal in the public imagination: the hacker (Wall, 2007).

Amid such fear and suspicion, a wealth of research has arisen on hacking and hacker culture across a diverse spectrum of topics. Many studies have adopted sociological and/or anthropological approaches toward the phenomenon. Some studies in this camp have examined hacking as a subculture that is rich with shared identities, practices, understandings, and organization (Coleman, 2010; Hollinger, 1991; Holt, 2009, 2010a, 2010b; Steinmetz, 2014; Steinmetz \& Gerber, 2014; Turgeman-Goldschmidt 2005; TurgemanGoldschmidt, 2011; Warnick, 2004). One of the most studied sociological approaches has involved exploring various philosophical and perceptual commonalities among hackers, most commonly through the investigation of the hacker ethic (Brown, 2008; Coleman, 2012; Coleman \& Golub, 2008; Himanen, 2001; Kirkpatrick, 2002; Levy, 1984; Warnick, 2004). Others have investigated the social construction of hacking over time, noting that popular culture has distorted the image of the hacker, generating consequences for the hacker community in the form of various legal/policy measures and crackdowns (Halbert, 1997; Skibell, 2002; Thomas, 2005). At the political economic level, hacking has been studied from a Marxist perspective, looking at how hackers-as intellectual laborers - fit within the dynamics of capitalism (Dafermos \& Söderberg, 2009; Söderberg, 2008; Wark, 2004). Finally, scholars have pointed out that hacking has also been carried out as a form of political activism (sometimes called hacktivism) (McKenzie, 1999; Meikle, 2002; Taylor, 2005; Van Laer \& Van Aelst, 2010).

Consistent with the focus of the criminological core, many studies have opted for more criminological analyses of hacking, often eschewing - though usually remaining sensitive to - the broader sociological and anthropological dynamics. For instance, research has investigated the more criminal or maligned parts of the hacker community such as the creation of viruses and malware, computer intrusions, website defacement, and identity theft (Furnell, 2010; Higgins, 2010; Holt, Strumsky, Smirnova, \& Kilger, 2012; Jordan \& Taylor, 1998; Nichols, Ryan, \& Ryan, 2000; Woo, Kim, \& Dominick, 2004). Criminological theory testing has been conducted on hacking-related behaviors (Bossler \& Burruss, 2010; Marcum, Higgins, Ricketts, \& Wolfe, 2014; Morris, 2010). Scholars have also examined the psychological characteristics of hackers (Rogers, Smoak, \& Liu, 2006; Schell \& Holt, 2010; Schell \& Melnychuk, 2010; Voiskounsky \& Smyslova, 2003). 
In this way, the hacker literature has matured into a diverse and increasingly robust body of knowledge, and within the literature, scholars have probed hacker demographics and backgrounds, either through brief discussions (e.g., Coleman, 2013; Söderberg, 2008; Taylor, 1999) or explicit focus (Bachmann, 2010; Holt, 2010a; Schell et al., 2002; Schell \& Holt, 2010). This review now turns toward explicating the more definitive research.

In their analyses and overviews, scholars have painted a relatively consistent portrait of hacker demographic characteristics (Bachmann, 2010; Schell et al., 2002; Schell \& Holt, 2010). Generally, these studies have found that hackers, despite popular culture portrayals to the contrary, are a diverse group in terms of age, with mean ages approximately around 30 years old with ranges from teens to sixties (Schell et al., 2002; Schell \& Holt, 2010). In addition, gender 2 and race disparities have been found in the hacker community, with White men being vastly overrepresented (Bachmann, 2010; Schell et al., 2002; Schell \& Melnychuk, 2010). Hackers are also reported to have relatively high levels of educational attainment; many possess at least a college degree (Bachmann, 2010; Schell et al., 2002). Approximately half have been married (Bachmann, 2010). Finally, hackers have been found to be employed in occupations with income levels averaging between $\$ 50,000$ and $\$ 57,000$ (Schell et al., 2002; Schell \& Holt, 2010).

Regarding development, previous studies examined features which appear to contribute to or appear as milestones in hacker development (Bachmann, 2010; Holt, 2010a; Schell \& Holt, 2010). Previous analyses found that hackers typically become involved in hacking at an early age (Bachmann, 2010; Holt, 2010a; Schell \& Holt, 2010). During these early stages of development, Holt (2010a) reported that becoming a hacker consists of four primary components: (a) initial interest; (b) access to technology; (c) engagement in "discovery and exploration;" and (d) attainment of an understanding of the "interrelated elements of computer systems" (Holt, 2010a, p. 113). Similarly, curiosity and a desire to tinker are often cited as motivations for early hacking (Bachmann, 2010; Schell \& Holt, 2010). Holt (2010a) also explored the ways in which hackers went about learning to hack. Perhaps the most important method of learning is "through 'trial and error' and 'playing with computers"' (Holt, 2010a, p. 115). Hackers largely seemed to rely on social networks, also, such as peer groups and hacker conventions for guidance (Holt, 2010a). Online communities and social groups were invaluable for many hackers in their development (Holt, 2010a). Additionally, Holt (2010a) discussed the importance of individuals demonstrating commitment to learning and developing as hackers, a commitment to that is a demonstration of autonomy as a creative thinker and learner in the activity.

Despite these noteworthy efforts, there still exists a need to further investigate hacker demographic and background characteristics. The hacker community is diverse, and it would be a mistake to consider that the subject is fully understood after only a few studies. This study advances the 
literature through its focus on socioeconomic class, school experiences, parental support and influences, as well as temporal exposure to hacking and the hacking community.

\section{Methods}

The current analysis was conducted using ethnographic field research which included participant observation and semi-structured field interviews. Beginning in June 2012, the researcher began attending public meetings for a hacker group based out of a major metropolitan area in Texas. For both ethical and pragmatic reasons, overt participant observation was used (Bulmer, 1982). Attempts at subterfuge may have jeopardized research efforts because hackers are often capable of unearthing deceit. Observational field sites included restaurants, bars, and a local hackerspace where members of this group and others congregated. Observations also took place at DEF CON 21 at the behest of members of the group. ${ }^{3}$ Following DEF CON 21 in August 2013, formal data collection ended which resulted in approximately 137 hours and 20 minutes of field observations with exposure periods ranging between 40 minutes to 17 hours.

While conducting ethnographic observations, 16 semi-structured interviews were also gathered among 14 members of this group or their close affiliates. Pseudonyms were assigned to each member and informed consent was gathered, although no documentation was maintained so their confidentiality would be more easily maintained (IRB approval for research was obtained). With two exceptions, all interviews were audio recorded and fully transcribed using dictation software and parroting. Interview times ranged from 58 minutes to 5 hours and 4 minutes. Many of the results presented in this study are derived from this interview data because of the targeted information direct questioning permits. The participant observation data, however, were instrumental in providing context and details otherwise absent in interview data.

To sift through the data in a systematic fashion, the analyses used in this study draw from grounded theory (Charmaz, 2006; Glaser \& Strauss, 1967). Involved is an iterative, multilevel approach to qualitative data analysis. This approach permits the isolation of patterns and categories to emerge organically from the data. In this manner, all of the qualitative data used in the study were subjected to at least three waves of coding to inductively isolate common patterns and categories. Atlas.ti, a software package explicitly designed for grounded theory analysis, was used to organize the data analysis (the software's analytic capabilities were not used; only organization structures were employed).

\section{Results}

Two general areas are explored in this study. First are demographic characteristics and disparities in the hacker community. These include participants' age, race, gender, perceived social class, and occupation. Second are developmental factors potentially influential in participants' maturation as 
hackers. Explored factors encompass educational experiences, perceived influences, and levels of support provided by their parents, as well as first exposures to technology, the concept of hacking, and the hacking community. The objective is to consider if these factors emerged as significant life events in their development and how these events unfolded. Table 1 provides summaries for many of the background characteristics discussed in this study.

Table 1. Demographic and background characteristics* 


\begin{tabular}{|c|c|c|c|c|c|c|c|}
\hline Name & Age & $\begin{array}{c}\text { Race/ } \\
\text { Ethnicity }\end{array}$ & Gender & Education & Occupation & $\begin{array}{l}\text { Marital } \\
\text { Status }\end{array}$ & $\begin{array}{l}\text { Has } \\
\text { Children }\end{array}$ \\
\hline Aidan & 27 & White & Male & Associate's & $\begin{array}{c}\text { Field } \\
\text { Technician }\end{array}$ & Married & No \\
\hline Danny & 23 & White & Male & In college & $\begin{array}{l}\text { Computer } \\
\text { security }^{* *}\end{array}$ & Single & No \\
\hline Gilbert & 24 & White & Male & Bachelor's & $\begin{array}{c}\text { System } \\
\text { administrator }\end{array}$ & Single & No \\
\hline Harvey & 41 & White & Male & Bachelor's? & $\begin{array}{l}\text { Independent IT } \\
\text { consultant }\end{array}$ & Married & No \\
\hline Jensen & 61 & White & Male & Bachelor's & $\begin{array}{l}\text { Technician/ } \\
\text { contractor }\end{array}$ & Married & \\
\hline John & 30 & White & Male & Some college & $\begin{array}{l}\text { Web hosting } \\
\text { manager }\end{array}$ & Married & No \\
\hline Keith & 27 & White & Male & In college & Technician & Single & No \\
\hline Miles & 37 & White & Male & Some college & $\begin{array}{l}\text { Security } \\
\text { research } \\
\text { scientist }\end{array}$ & Single & No \\
\hline Pete & 35 & White & Male & $\begin{array}{c}\text { Honorary } \\
\text { doctorate } \\
\text { (otherwise, } \\
\text { no advanced } \\
\text { degrees) }\end{array}$ & $\begin{array}{l}\text { Computer } \\
\text { security } \\
\text { researcher }\end{array}$ & Divorced & Yes \\
\hline Raj & 37 & Indian & Male & Master's & $\begin{array}{c}\text { Software } \\
\text { development } \\
\text { customer facing }\end{array}$ & Single & No \\
\hline Rick & 50 & White & Male & Bachelor's & $\begin{array}{l}\text { Software } \\
\text { engineer }\end{array}$ & Married & Yes \\
\hline Roger & 27 & White & Male & In college & Retail & Single & No \\
\hline Russell & $\sim 30$ & White & Male & Bachelor's & IT technician & Married & Yes \\
\hline Susan & $\sim 37$ & White & Female & Bachelor's & IT Management & Divorced? & Yes \\
\hline \multicolumn{8}{|c|}{$\begin{array}{l}\text { * Some participants were vague or unwilling to be specific on certain demographic } \\
\text { characteristics. Thus, approximations are presented for some (designated by ' '). } \\
\text { In addition, some participants did not volunteer certain information. In these } \\
\text { instances, the entry is left blank. } \\
\text { ** In school working towards a career goal. Ideal occupation listed. }\end{array}$} \\
\hline
\end{tabular}


Table 1 (cont.). Demographic and Background Characteristics*

\begin{tabular}{|c|c|c|c|c|c|c|}
\hline Name & 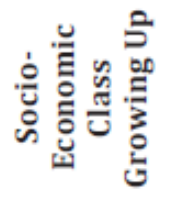 & 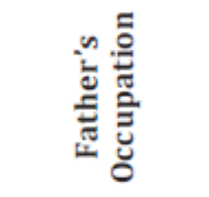 & 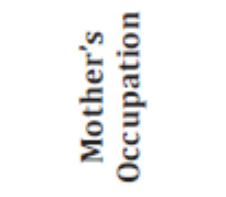 & 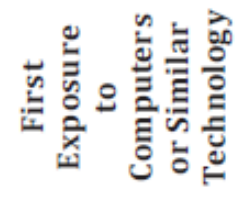 & 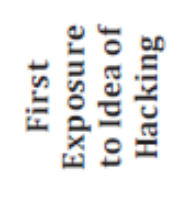 & 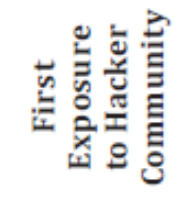 \\
\hline Aidan & Middle & $\begin{array}{l}\text { Automotive } \\
\text { mechanic }\end{array}$ & $\begin{array}{l}\text { Respiratory } \\
\text { Therapist }\end{array}$ & $\sim 5-7$ & $\sim 12-14$ & $\sim 13$ \\
\hline Danny & Middle & $\begin{array}{l}\text { Engineer } \\
\text { (Ph.D.) }\end{array}$ & Jeweler & $\sim 10-11$ & $\begin{array}{l}\text { Seventh } \\
\text { grade }\end{array}$ & $\begin{array}{l}\sim \text { Seventh } \\
\text { grade }\end{array}$ \\
\hline Gilbert & Middle & $\begin{array}{c}\text { Food } \\
\text { scientist }\end{array}$ & Teacher & $\begin{array}{l}\text { Elementary } \\
\text { school }\end{array}$ & $\begin{array}{c}\text { Before } \\
\text { junior high }\end{array}$ & College \\
\hline Harvey & Middle & $\begin{array}{c}\text { "The } \\
\text { professions" }\end{array}$ & Homemaker & $\sim 6$ & $\begin{array}{c}\text { Before age } \\
14\end{array}$ & Early 1980 s \\
\hline Jensen & Middle & CPA & Portrait artist & Grade school & $\begin{array}{l}\text { During } \\
\text { college }\end{array}$ & $\begin{array}{c}\text { In the } 1970 \text { s } \\
\text { with phone } \\
\text { phreaking }\end{array}$ \\
\hline John & Middle & $\begin{array}{l}\text { Stay-at-home I } \\
\text { parent }\end{array}$ & Lab technician & $\sim 5-6$ & $9^{\text {th }}$ grade & $\begin{array}{c}\text { Senior year } \\
\text { in high } \\
\text { school }\end{array}$ \\
\hline Keith & Middle & $\begin{array}{l}\text { Computer } \\
\text { programmer }\end{array}$ & $\begin{array}{l}\text { Stay-at-home } \\
\text { parent }\end{array}$ & $\sim 6-7$ & $\begin{array}{l}\text { End of } \\
\text { elementary } \\
\text { school }\end{array}$ & $\sim 24$ \\
\hline Miles & $\begin{array}{l}\text { Upper- } \\
\text { Middle }\end{array}$ & $\begin{array}{c}\text { Middle- } \\
\text { management }\end{array}$ & $\begin{array}{c}\text { Stay-at-home } \\
\text { parent }\end{array}$ & ～Kindergarten & $\sim 12-16$ & Late 1980 s \\
\hline Pete & Middle & Marine & $\begin{array}{l}\text { Stay-at-home } \\
\text { parent/book } \\
\text { retail }\end{array}$ & $\sim 6-8$ & $\begin{array}{c}\text { Since he } \\
\text { was a child }\end{array}$ & $\sim 16-17$ \\
\hline Raj & $\begin{array}{l}\text { Upper- } \\
\text { Middle }\end{array}$ & $\begin{array}{l}\text { Medical } \\
\text { doctor }\end{array}$ & Beautician & $\sim 12$ & $\sim 7$ & $\sim 26$ \\
\hline Rick & $\begin{array}{l}\text { Upper- } \\
\text { Middle }\end{array}$ & Engineer & & $\begin{array}{l}\text { Elementary } \\
\text { school }\end{array}$ & High school & High school \\
\hline Roger & Middle & $\begin{array}{l}\text { Software } \\
\text { engineer }\end{array}$ & Office sales & $\sim 8$ & $\begin{array}{l}\text { Teenage } \\
\text { years }\end{array}$ & $\begin{array}{l}\text { Teenage } \\
\text { years }\end{array}$ \\
\hline Russell & Middle & $\begin{array}{l}\text { Automotive } \\
\text { mechanic }\end{array}$ & $\begin{array}{l}\text { Mortgage } \\
\text { company } \\
\text { employee }\end{array}$ & $\sim 9-10$ & $\sim 12-14$ & 21 \\
\hline Susan & $\begin{array}{l}\text { Lower- } \\
\text { Middle to } \\
\text { Middle }\end{array}$ & $\begin{array}{l}\text { Computer } \\
\text { engineer }\end{array}$ & Homemaker & $\sim 4-5$ & Unsure & College \\
\hline
\end{tabular}

* Some participants were vague or unwilling to be specific on certain demographic characteristics. Thus, approximations are presented for some (designated by ' $\sim$ ').

In addition, some participants did not volunteer certain information. In these instances, the entry is left blank. 


\section{Developmental factors}

Beyond demographic and background characteristics, the participants were also asked about aspects of their lives which may have influenced their trajectory as hackers. Developmental factors explored in this study include their educational experiences, parental relationship dynamics, as well as their temporal exposures to technology, the concept of hacking, and the hacker community.

\section{School experience}

A number of the participants discussed their experiences in education, both in grade school and higher education. School performance spanned between average grades from a $\mathrm{C}$ to an $\mathrm{A}$. What seemed to make a difference in the student's performance was the educational environment provided in the schools and the perceived usefulness of what was being taught. In grade school, the interviewees reported a wide range of disparate experiences. Public schools were largely associated with negative experiences such as anti-educational peer climate. "Busy work," work done to keep a student busy rather than intellectually engaged, was also cited as a problem, as Keith explained:

Essentially they gave you a large packet of work ... The packets were largely worksheets and fillin-the-blank problems and things like that that were just essentially "look through the book for this keyword and fill it in." There was nothing engaging at all about it so I didn't bother.

In these educational settings, particularly in public schools, some of the interviewees reported feeling unengaged with the material; a lack of challenge was present. Jensen described a sense of apathy toward grade school because it was too easy which supposedly induced him to be an "underachiever" with "high IQ versus low performance."

Other interviewees reported more positive experiences in education, which tended to involve various private schools. These schools were thought to be more focused and more engaging. John described his experience in a Catholic high school:

There is definitely a different atmosphere in terms of what you're responsible for and not being held to a lot of standards that are ... And I ... Having a bit more focused expectation on the kids, you know ... saying, "John, you are responsible for these few things. Either you do it or you don't do it. And that determines whether you succeed," [and that] lends itself to a better education. And the smaller class sizes. You know your teachers.

In this explanation, John expressed a sense of satisfaction because his education had a more customized approach to learning and had smaller classes. Roger also compared his dismal public school experience with that of private school:

That was actually a fantastic experience. I was learning at a much quicker pace. Classes were smaller and more intimate. In my grade level there was about eight or nine of us. Sometimes 
there were a few classes that mashed up with a few people of lower grade levels so they would run up to like 13 or 15 . And it was still pretty big. Teachers were very knowledgeable and we were learning ... we were learning at a much more rapid rate. We were learning ahead of grade levels. I was passing classes with 90 s. There was no homework. It was very ... It was very efficient and very useful.

In this experience, school was more enjoyable because of the more efficient learning structures and the absence of what Keith identified as "busy work." Overall, the education experience was considered better when the environment was perceived as engaging, challenging, and efficient.

Some of the interviewees' experiences in higher education were also problematic. The idea of alleged uselessness of some courses was reinforced by Rick:

By that time I was already way smarter about computers than almost anybody else that was in school because very few people actually had computers ... So, when you go to college-you've been to college [gesturing toward me]-you go and they tell you, "okay, you're a freshman. Well, everybody has to take English and History and Political Science and all of these other crappy-ass classes that nobody wants to take. Everybody has to take them." And so I did that like my first year and suffered through a bunch of classes but I had a computer class and I aced it and was like, "this is awesome!" But you can only take one and I'm like, "what? That's kind of fucked."

In this experience, Rick expressed frustration with being forced to take classes he was not interested in; learning, in general, was not the objective. Rather, his desire was to learn about a specific topic of interest. Overall, the interviewees expressed appreciation for school when the environment endorsed challenging, engaged learning over topics in which they were interested. School experiences seemed to be viewed negatively if the learning was overly simplistic, unengaging, unchallenging, or perceived as irrelevant.

\section{Parental support and influence}

One objective of studying the background factors of hackers was to ascertain the influence and/or context the interviewees' parents provided for their children's development as hackers. A description of a potential relationship between parents' occupations and the occupational pursuits of the participants is provided. Second are descriptions provided by the participants of their perceived levels of parental support for their interests in technology and/or hacking. Support, however, concerns a more direct relationship between parental actions/vocalizations and hacker interests. Despite perceived levels of support, parents may act in ways which otherwise influence hackers-indevelopment. As such, this study also explores participants' descriptions of perceived parental influence as well. 


\section{Parents' occupations}

First, there seems to be a relationship between their parents' occupations and the interests held by the participants. Twelve out of the 14 interviewees had at least one parent with some sort of technically oriented job; an equal proportion possessed some sort of white-collar job. The jobs held by their parents often involved some sort of hands-on and/or scientific orientation.

These jobs seem to have influenced the development of some of the interviewees. For example, Aidan stated a strong interest in things like robotics and hardware hacking and his father worked as a mechanic doing machine repair as well as repairs on automotive vehicles. Similarly, Russell's father had worked on aircraft maintenance and repair while in the Marines. Russell described himself as a "builder" interested in working hands-on with hardware and such, doing some of this in his previous job working in the Navy. In the area of software, Keith and Roger both had fathers who were involved in computer programming, a domain both of them shared interests in as well. While the relationship between an interviewee's parents' occupations and their own interests were not perfectly associated, there seems to be a link for some of the participants.

\section{Perceived parental support}

The perceived levels of support parents provided for technological development were also explored in this study. On this topic, 8 interviewees asserted that their parents were overtly supportive of their interests in learning and technology. Roger, whose father was also a member of Union Hack included in this study, explained, "I got into computers at a young age thanks to parents pushing me into it." For these participants, their parents actively supported their involvement in computers and related endeavors.

Five participants described their parents as not explicitly supporting their interests but also not discouraging them either. These parents were viewed positively because they implicitly supported their efforts to learn about technology and hacking by not interfering or simply by tolerating the behavior. Pete described how his parents encouraged him to learn, even if they did not necessarily understand what he was learning:

They've always ... like, my mom has always encouraged my intelligence ... And so she's always encouraged my music and the outlets of focus and helped me get structure. And she never really said, "don't be involved in computers." And I think she understood ... she may not have understood what it is but I think she allowed for it to flourish. And my dad ... you know, I used to ask a lot of questions when I was young. And my parents would do their best at answering them. So, I think, yeah ... I think both of them really tried to encourage the constant effort of learning.

In this context, Pete's parents were supportive of his efforts to learn. They may not have been overtly supportive of his interest in computers due to their own lack of understanding, but they implicitly 
supported the behavior by providing an environment which "allowed for it to flourish."

Some parents provided both explicit and implicit support during technological development. For instance, Gilbert explained that, "at first my dad taught me how to use the computer. We had our first computer ... Yeah, he taught me how to run commands from DOS and how to run things." When I inquired further about how his parents supported his involvement in computers, he elaborated that later in his childhood, "I think to some extent it was just letting me explore without ... They didn't try to stop me in any way ... 'he's interested in this, let him do it;"' his father helped to push him into computers but then stepped back and allowed for Gilbert's interest and curiosity to take over.

Contrary to the previously described experiences, one interviewee, Miles, asserted that his parents were unsupportive of his efforts to learn outside the classroom:

There were some complicating issues involving my family where I was ... I didn't have ... assistance from my parents and ... In dealing with those things. And I was told, you know, basically everything was my fault so ... But ... I didn't really have a particularly social, supportive family.

He further chronicled his parents' perceptions of his involvement with computers, "they didn't understand it. I think that they ... I think that they saw it as a word processor ... and not something ... not something to learn about in and of itself." Miles reported that he had to overcome his parents' resistance to computers rather than be nurtured and supported by them.

Harvey also faced opposition from his parent; while initially not disapproving, they became more unsupportive after he got in trouble for hacking. He described his parents as

specializing in staying unaware of most things at that point. And I don't think it was because they actually knew what was going on ... I don't think they really noticed until they got calls from people who are interested in law enforcement. And then ... They started to take notice and think things were bad. But I mean, you know, at that point I had been phreaking for a while and I knew how to wire up an external phone line and how to hide a modem ... There was not much a parent could do.

He elaborated further by stating, "I would say at the end of it, my parents really wanted me to stop playing with the computer."

\section{Perceived parental influence}

Beyond supporting participants' development as hackers, either through direct encouragement or providing an environment where they were free to pursue their interests, parents can also influence the proclivities of burgeoning hackers in other ways. Such influence is buried in the implicit activities 
which children are particularly adept at observing. Even though 8 interviewees described their parents as openly supportive of their development, 10 indicated that their parents were at least influential. One mechanism of influence involved providing an environment which would foster interests in learning, building, and tinkering. John described learning to appreciate problem-solving and tinkering through his father:

My dad ... putting kids through private school ... is a pretty big financial drain on a single income family. And ... so, my dad worked on a lot of things just to keep things going. And ... he had ... a pretty good approach to problem-solving. So, a lot of solving problems and kind of ... MacGuyvering things came from him.

In essence, according to John, his father influenced his appreciation of problem solving and repairing.

Although Miles stated that his parents provided him with little to no support for his interests in learning and hacking, he admitted that his parents still had an influence:

My father was, you know, a reasonably intelligent guy and he had a lot of interests ... You know, hunting, fishing, woodworking ... you know, he could fix the lawnmower or he could ... He could do shit. So, from when I was really very, very little I always had, you know, like, a little hammer and some nails and, you know, I could always make stuff.

Miles's parents were described as influencing his interests in security-related issues because his mother "was kind of afraid of everything" which supposedly encouraged a distorted fear of threats. In addition, he described that his curiosity about security may have been triggered by his parents because they "would always be in my shit." Those parental experiences allegedly triggered an interest in constructing and deconstructing security systems through hacking. Miles still claimed to have been shaped by the context his parents provided despite having an unsupportive family environment.

Parental influence, however, may not result in a positive transfer. There is the possibility that parents' interests may negatively influence the development of hackers and their interests in technology. At an early age, Susan described being exposed to computers and instruction in programming. As she left for college, however, the exposure to computers temporarily drove her away from working with them. When asked if her parents influenced her interests, she stated:

Actually [it] had the opposite effect. That's why my undergraduate degree is in psychology. So, I just had a lot of exposure to computers. All growing up they were all very easy and, for me, it was a normal part of life. And I think if you look at computer people, you see that they aren't very social and they are a little bit nerdy. And kind of like the way I rebelled against that was to pick up something that was very socially-oriented. 
In this scenario, Susan described how her parents, particularly her father, influenced her interests in computers and her skills as a programmer. The problem was that this influence eventually drove her away. Although she was still relatively skilled, she chose to focus on the social components of the hacker community.

Only 2 of the interviewees asserted that their parents did not have an influence on their interests in hacking and computers. Aidan summarized this absence when asked about the influence his parents' may have had:

Not at all, really. Neither one of them are very technically savvy. Pretty much nobody in my family was really very technically savvy. So, I mean, the personal computer thing wasn't ... I pretty much did all of that on my own. And it was, pretty much getting everything myself. There wasn't really interest in it in my family.

Raj described his parents' influence a similar manner, "Yeah, that was all me. They weren't pushing me to ... to learn about it [computers] one way or the other." In both cases, the interviewees argued that their parents had no or little influence on their interests in technology and hacking.

\section{Exposure to technology, hacking, and the hacker community}

To help understand the background context the interview participants operated within, this study also examined three temporal milestones of interest which must occur at some point in a hacker's development which include their first exposure to computers or related electronics, to the idea of hacking; and to the broader hacker community. These periods are discussed sequentially. Since the interviewees were asked to recall the age or time period of exposure, the numbers often lack specificity. However, the results are still useful because they provide a temporal approximation.

\section{First exposure to technology}

The ages in which the interviewees reported first experiencing technology, either mechanical or computer, were generally around pre-adolescence, ranging from approximately 4 to 12 years old. For 10 of these participants, first exposure occurred at home. The experiences are often recalled with a sense of nostalgia. Aidan described his first experiences with computers centered around his father picking up a TI (Texas Instruments) machine that

took cartridges similar to Atari cartridges. It had the gold fingers on it and ... you had to do everything manually through the keyboard. It plugged into a RGB video port on your TV so you could load it up on the TV and you had to basically manually do everything on there. You couldn't save but it was very similar to Atari and had all kinds of stuff. I can't remember a lot but you could pretty much do anything on that. 
Similarly, Keith described his first exposure.

I was probably six or seven ... somewhere in that general vicinity when I first was using a computer on my own. I remember being amazed when my father brought home his first laptop. It was one of the old ones that ... brand DOS. It had the hinge in the middle of the computer where the screen was only, you know, half the depth of the computer. I know that when I was probably eight or nine we got our first upgrade for that computer, where I think his job actually furnished a new computer for us. I wound up taking the old one apart [laughs] and getting into a rather large amount of trouble for doing so.

One participant, Miles, described his first experience occurring in school when he was in kindergarten. Directly tying the relationship between class and exposure to technology, he describes his first exposure.

By a series of coincidences combined with [the] social strata of my classmates ... we had probably the first computer lab in the city. And we started out with crap like MasterType and MathBlaster on the original Apple II, I think, even before the 2e and 2+ came out.

Harvey stated that his introduction to computers occurred around the age of 6 through some friends in his neighborhood, "I knew a number of people who had Apple IIs ... and, before that, there were things like Kaypros and a number of those older CPM machines because we were in a neighborhood with a lot of engineers." In this case, his associations with friends with parents in technologydependent occupations initiated him to computers.

Related to the importance of parental occupations, like those described by Harvey and Keith, Rick remembered going to his father's place of employment and watching a massive computer at work.

So, he brought me down there to watch with this punch card thing to put it in the things. They gave it to the monkeys behind the glass [the computer engineers] who ran it and we sat and waited for ... at the time it was a form of early daisy wheel printer but it, you know, was this spinning disk with all the letters on the outside and it when "bahp, bahp, bahp, bahp, bahp, bahp, bahp" [printer sounds] and I watched that for an hour and thought it was the coolest thing ever.

In this case, Rick describes being fascinated with the computer and told about his first hands-on experience occurring in a school setting.

But my first experience using [emphasis added] a computer was actually in elementary school where they actually brought a teletype terminal and clunked it down in the middle of the classroom. It was the, I guess it must've been fifth grade, it was the special day for people to 
come in and tell you about stuff when you are going to grow up and kind of things, and somebody came in to tell us about this computer. So, we played Adventure on the Teletype, the Crowley and Woods original.

Video games seemed to play a key role in some of the participants' first experiences with computers (see also: Holt, 2010a). Rick described playing Adventure on the Teletype. Miles's first experiences involved educational games. Aidan recalled his experiences using the old Atari 2600, a gaming console, among some of his earliest memories involving computers. John described his first exposure involving his father's Commodore 64 and the game haunted hill. While Harvey was never a big gamer, he communicated the importance that video games hold in triggering interest for a number of hackers, "I think video games got us, a lot of us, into it because that was how you started learning to write your own code and how to de-protect it." Many video games involve the use of various copy protection methods. Early introductions into hacking activities, for some, emerged from learning circumvention techniques for these measures (see also: Downing, 2011).

Most of the introductions to computing technology occurred at an early age for the participants, during their pre-adolescence, which is similar to the findings of Holt (2010a). Young children are often particularly curious and more easily fascinated. To develop as a hacker, it may be important to harness childhood fascination, parental support, and surplus time at an early age to foster the competencies necessary to be successful as a hacker later in life.

\section{First exposure to hacking}

For most of the interview participants, their introduction to the idea of hacking came after their first experiences with computers $(n=8)$. Three of the participants' initiations to computing and their exposure to idea of hacking were so close together that the temporal configuration is difficult to delineate. One participant was uncertain of when he first heard the term so temporal ordering could not be established. For interviewees who did recall when they were first introduced to the idea of hacking, 8 stated the experience occurred around adolescence (approximately 12-16 years old), 4 stated pre-adolescence (before 12 years of age), and 1 older participant claimed post-adolescence (college).

In addition to time frame of exposure, 8 of the interviewees also discussed how they came across the term hacking (the others were uncertain). For some, their introduction to hacking, as a formal concept, emerged from their social connections $(n=3)$. Harvey described creating war dialers and then being told that the activity was considered hacking. "But anyway, we were writing this little war dialer to dial all night long and return numbers ... interesting numbers to us. And I remember being told that was hacking." Here, being in a social setting along with other people who had similar interests is what 
introduced him to the idea of hacking. Harvey was actually engaging in hacker-like behaviors before he realized that this was hacking. Most of the other interviewees fell into similar temporal ordering.

Some participants came across the idea of hackers through media $(n=4)$. Russell described hearing the term while seeing the movie on a date.

I've always been interested in how things worked but I remember seeing ... seeing the cheesy movie "Hackers" in the theater ... And I remember going to see that and I was like, "I never thought of making machines do something that they weren't supposed to do." And I do remember that it was kind of pivotal like, "there is a hacker subculture ... that are all about computers." And I was like, "I got to look more into that." And so that is kind of my ... the movie "Hackers" actually had an influence on me [laughs].

In this scenario, Russell, like Harvey, was already doing many things some would consider to be in the realm of hacking. He became more familiar with the term and grew interested in pursuing the hacker culture as a result of his exposure to a movie. For some, the 1983 movie War Games was their introduction to hacking, a similar experience for other hackers, as Coleman (2012) describes:

Apparently the movie appeals to a slew of nerdy types across Europe, Latin America, and the United States, leading them to incessantly demand from their parents a PC and modem, which once they got, commanded their attention while they were logged on for hours on Bulletin Board Systems (BBSes). (pp. 105-106)

Media constructs simultaneously arose from the hacking community as well as engendered further growth and popularity of hacking recursively.

Unlike the previously discussed cases, Danny described first coming across the hacker community through exploration on the Internet:

I've been poking around in them [computers] since I was maybe ten or eleven but I didn't really find out what I was doing, or even really what "hacking" was, until about seventh grade. That was when I started reading “The Happy Hacker” website by Carolyn Meyer ... After that, I eventually moved on to textfiles. org and from there to Phrack, Union Hack, and HackThisSite, and from there to where I'm at now.

In this case, his introduction was through hacker-created content delivered through the Internet such as The Happy Hacker, a website specifically dedicated to providing a safe place for fledgling hackers to build their skills. 


\section{First exposure to hacker community}

For almost all of the interviewees, their introduction to the hacker community occurred after their first experiences with computers and the idea of hacking. Eight were first introduced through inperson hacker groups. Of these participants, 3 were introduced through Union Hack specifically. Another 6 had their first experiences electronically, either on the Internet or through early BBSs. The majority of these interviewees came across the community around adolescence $(n=8)$. The remainder were exposed around college or sometime in their mid-20s $(n=6)$.

As previously stated, some of the interviewees were introduced to the hacker community through electronic means such as BBSs and online forums. Miles described his first experience with the community through BBSs:

I think that was about the time I got my first modem and started dialing into BBSs. And at that point, now I had ... people, you know, somewhat that I could communicate with. And that's actually, you know, where I met some of my best friends.

His experience with groups which met face-to-face came later. As BBSs became less common and the World Wide Web became prominent, more hackers found the community through the Internet, such as through online forums. As Aidan elaborated in response to being asked about his first experience with the hacker community,

the hacking community ... was online forums. It was after the BBS days. There wasn't ... BBSs weren't a big thing but it was starting to get more geared towards forum based stuff so ... I was involved in several of those.

In these cases, the subjects were already familiar with the idea of hacking but became involved in the hacker community through electronic means. An overt physical hacker community was not readily apparent and, as such, using telecommunications to connect to others with similar interests were used. Unlike the other participants, Danny's introduction to the hacking community co-occurred with his first experience with the idea of hacking.

Some persons, however, were introduced to face-to-face hacker groups as their first exposures to the community. Susan described being taken to her first Union Hack meeting in college, where she took up a psychology/ neuroscience major to break away from computers initially.

I think it was probably ... It probably wasn't until college when someone brought me to a Union Hack meeting ... It was a bunch of people hanging out in [location omitted] talking about the ... I mean, a lot of it was nostalgia and stuff people had done on BBSs and that was kind of my coming up to speed with it. Just people talking about different things they did. I think as I started going to more and more meetings there were actually people who are very active. 
Similarly, Gilbert described his first experience with a hacker group (his introduction to the community), "I guess I would say my first serious involvement with what I consider the hacker community would be ... Wouldn't be until college when I joined a [programming group]. So that was inperson." John had his first exposure through a hacker-zine which then led him to a Union Hack group meeting. In all of these cases, the authors were introduced to a face-to-face group after they were already personally interested (or at least skilled) in computers and were already familiar with the idea of hacking.

\section{Discussion}

In this study, multiple background and developmental factors in the lives of the participants were explored in order. On one hand, this study sought to reevaluate demographic and developmental features which had been explored in previous analyses (Bachmann, 2010; Holt, 2009; Holt, 2010a; Schell et al., 2002; Schell \& Holt, 2010; Taylor, 1999; Turkle, 1984). In this regard, this study's findings echo previous analyses. On the other hand, this study also sought to investigate features which had not previously received tremendous attention including (1) class dynamics, (2) parental support/influence, and (3) introductions to the idea of hacking and the hacker community. These dynamics convey a broader developmental context than had previously been explored.

Regarding demographics, age was found to vary, ranging from 23 to 61 with an average in the mid 30s, mirroring previous analyses (Bachmann, 2010; Schell et al., 2002). Similarly, the current analysis reinforces previous findings of a prominent gender disparity throughout the hacker community (Bachmann, 2010; Jordan \& Taylor, 2004; Schell et al., 2002; Taylor, 1999; Turkle, 1984). Most of the participants were White as well, pointing toward the larger race disparities throughout the community (Bachmann, 2010; Schell et al., 2002; Schell \& Melnychuk, 2010; Söderberg, 2008; Taylor, 1999). Additionally, most of the participants in this study considered themselves to be middle-class and were employed legitimately in technological occupations. $\frac{4}{}$ The majority had higher education degrees or were working toward them (see also: Bachmann, 2010; Schell et al., 2002). Notable demographic imbalances exist in the data and seemingly throughout the hacker community, particularly along gender, race, and socio-economic class lines. Drawing from previous literature and other supporting evidence, this analysis offers potential explanations for these gaps.

Concerning gender, Taylor (1999) commented on the relationship between hacking and gender and offers possible reasons for the gender disparity noted in his study and in the current analysis. As he noted, there are three potential reasons for this gap. One is a societal factor such as training children into gender roles which tend to favor technical development as a masculine endeavor. Another is that the masculine (and sometimes misogynist) environment of hacker culture may deter women from participating. The final reason, related to the previous, involves the often masculine, technical, and coded language used by men in the hacker community and STEM (science, technology, engineering, 
and math) areas which may act as exclusionary toward women. As a result of these factors identified by Taylor (1999), women may be steered away from participation in hacker culture.

The latter two dimensions discussed by Taylor (1999) parallel Turkle's (1984) discussion of hacking that involves a culture of computational masculinity which is dominated by young men. Such a culture is described as concerned with various levels of technological and relational control. Similarly, Jordan and Taylor (2004) summarized the issue; "While it would be misleading to brand all hackers sexist, there is no denying the competitive, masculine nature of the hacking community" (p. 117). Women may therefore be dissuaded from participation, though participant observation indicates that presence and acceptance of women may have changed (at least slightly) in the hacker community since these previous studies (Jordan and Taylor, 2004; Taylor, 1999; Turkle 1984). Further research is needed to probe gender in the hacking community, with a particular eye toward gender role socialization explanations generally (Schell \& Holt, 2010).

The majority of hackers in this study were found to be White, a finding similarly reflected in previous research (Bachmann, 2010). While research on potential reasons for this disparity in the hacking community is lacking, research on racial/ethnic underrepresentation in STEM fields may provide insights, since the similarities between the two areas are notable. While the gap is closing, there is a prominent underrepresentation of minorities, particularly African Americans and Hispanics, in STEM areas (National Science Foundation, 2013). Reasons for this underrepresentation "are complex and exist at several levels (individual, family, the educational system, the workplace, and in society at large)" (Burke \& Mattis, 2007, pp. x-xi). Various environmental, institutional, and/or structural barriers exist which obstruct racial minority participation; similar obstacles may exist for membership in the hacker community. Future research should investigate this issue in greater depth.

For socio-economic class, all of the participants in this analysis self-identified as middle class; Söderberg (2008) stated, "[a] quick glance is all it takes to confirm that the social base of the hacker movement is heavily skewed towards middle-class males living in the West" (p. 28). While the cost of technology is declining over time, access to computer hardware, particularly during the period most of these participants were children or adolescents, is often costly and out of reach for many without some sort of surplus finances. For example, some of the participants in their late 30s and older grew up when few households had access to computers compared to today. The Apple II was one of the first personal computers some of the older participants had access to. This computer was approximately $\$ 1,200$ dollars (for a bare-bones model) in 1977 and was one of the first home computers to gain even a modicum of popularity. According to the Bureau of Labor Statistics inflation calculator, a $\$ 1,200$ computer in 1977 would cost approximately $\$ 4,631.23$ today. This estimate does not account for the cost of any additional hardware, software, or any other devices necessary for learning. In short, there seems to be a cost barrier to entry for hacking. 
There are certainly members of the hacker community who circumvent these barriers and find ways to access technology; the origins of the hacker community at MIT involved instances of early hackers finding ways to access the enormously expensive computers available at the time (Levy, 1984). Additionally, some hackers engage in scrounging or dumpster diving to acquire parts. Regardless, because it is easier for a person from a middle-class background to access technology, hacking appears to be a predominantly middle-class phenomenon, at least in the United States.

Beyond demographic characteristics of hackers, this study also examined developmental factors which may have helped influence interviewees' participation in hacking. The results of school experience data show that hackers seem to fare better in educational environments that challenge and promote specialized learning in areas of their interest. Additionally, efficiency seemed to be valued in education; work which did not directly contribute to learning (i.e., busy work) was frowned upon. While hackers generally tended to express a preference for private schools over public, this is a result of the particular educational environment these schools were seen to provide rather than any particular aversion to government-sponsored education generally.

Data on parents were also explored as a potential influential factor in development as hackers. Participants' parents generally held technological occupations. This finding indicates that parents may share and/or transmit proclivities toward technology. At the very least, such occupational preference may have demonstrated to participants that work with technology was a viable life choice. Parents' occupations also further solidify the connection between hackers and middle class status. Most parents often held traditional middle class occupations which would provide the funds to afford technology.

Additionally, the participants' accounts of parental support and influence point to an environment that, for most, fostered the interest and autonomy to engage technology made available to them. Generally parents appeared to support the participants' engagement with technology or, at a minimum, did not obstruct their engagement. Even if support was not provided, many hackers reported parents at least influencing their interests and development in various ways. Overall, while measuring the magnitude of any sort of effect parents may have had on participants, there seems to be a relationship which, for most, nurtured their development and interests.

Finally, participants were asked about their introductions to computing (or related) technology, the idea of hacking, and the hacker community. The hackers in this study reported first exposures to technology at an early age, usually pre-adolescence (see also: Holt, 2010a; Schell et al., 2002). Such exposure seems to correlate with socio-economic class positioning; middle-class families are ones more likely to possess excess funds in which to buy high technology equipment and thus provide

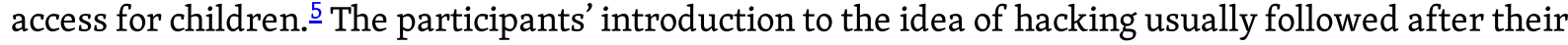
first experiences with computing technology, often occurring during adolescence. Introductions to the 
hacking community were mostly cited occurring during or immediately following adolescence. These results indicate that, generally speaking, there seems to be a temporal ordering for exposure and development that begins at an early age. Interest in technology comes first, and then, during adolescence, a person drifts toward hacking as a behavioral and cultural outlet. Once the hacker subscribes to the notion of hacking, participation in the community may follow; some associate with other hackers before self-identification as a such (which seems to occur in tandem with exposure to the idea of hacking). Previous research has similarly indicated that hacker development is heavily linked to social relations; despite popular beliefs about hackers being anti-social loners, many hackers share friendship/peer networks that include other hackers (Holt, 2009; Holt, 2010a; Holt et al., 2012).

\section{Conclusion}

This analysis serves to qualitatively investigate background factors in the lives of hackers, expanding previous research (Bachmann, 2010; Holt, 2010a). Understanding the contexts from which hackers emerge is valuable because such people do not emerge from nowhere, ready to code and/or crack. Studies that attempt to explain hacker behaviors which do not account for their backgrounds and history may fail to consider important variables and, thus, come to problematic or even erroneous conclusions. Demographic and developmental characteristics may be worth investigating in future analyses to provide a foundation for explanatory frameworks necessary to fully understand hacking as both an individual level and cultural phenomenon.

The examination of background factors also offers theoretical insights and potential avenues for further theoretical analysis. For instance, the early development of hacking interests and associated behaviors may lead to implications from a life course criminology perspective (Laub \& Sampson, 1993; Sampson \& Laub, 1992). While the sample is limited, the results indicate that hacking is an activity and mindset which begins at an early age and is reinforced by various life events, each one seeming to further pull individuals into the hacking community. The current study demonstrates that such events and their order seem to matter in the development of hackers.

The research also notes that peer relationships are sometimes significant; some participants discussed learning to hack and being exposed to the hacker community through peer networks. As such, social learning theory may be a viable perspective (Burgess \& Akers, 1966) and has already been explored as a potential explanatory apparatus for hacking-related behaviors (e.g., Marcum et al., 2014). Considering the early age in which hacker proclivities seem to develop, however, the birds of a feather hypothesis may also be viable, thus making developmental criminological perspectives worth pursuing.

The seeming importance of class also indicates that studying hacking from a political economic perspective is viable. Previous analyses have already begun exploring the political economy of hacking, particularly from a Marxist framework (Dafermos \& Söderberg, 2009; Söderberg, 2008; 
Wark, 2004). This study gave greater focus to the immediate social milieu surroundings hackersparents, school, etc. - but future analyses might consider the macro-structural context surrounding hacking as well in light of the seeming importance of social class.

To conclude, several limitations confronting this study need to be elucidated. First, this study was faced with a small sample size for the interview data. In depth field research is often plagued with this limitation; however, the depth of data obtained may off set this problem. Additionally, the demographic characteristics and some of the other factors explored in this study parallel previous research on hackers (Bachmann, 2010; Holt, 2010a). The ages of the hackers when they were first introduced to the subject and the dates used in the data may be unreliable, because subjects were asked to recall these instances from their pasts. That said, the discussions provided in this analysis do not attempt to make assertions beyond what the limitations permit, and the recollections were reliable enough to allow for the general examinations which occurred in this study. This study was additionally limited in the ways that ethnographic field research is commonly afflicted, and thus these limitations were not explained here further.

Despite the limitations present, this research indicates that background and developmental factors deserve further exploration to further refine our understandings of the creation and upbringing of hackers. The analysis demonstrates that hackers are not ahistorical beings. Rather, they emerge from a context and develop along a trajectory toward hacking. As such, researcher would be wise to pay heed to these (and other) factors when examining the development of the hacker. This area of research is still in its relative infancy in criminal justice and criminology. The current study is one more step forward along the path to creating a theoretically (and hopefully practical) useful body of knowledge on hackers and related populations.

\section{References}

Bachmann, M. (2010). Deciphering the hacker underground: First quantitative insights. In T. J. Holt \& B. H. Schell (eds.) Corporate hacking and technology-driven crime: Social dynamics and implications (pp. 105-126). Hershey, PA: IGI Global.

Bossler, A. M. \& Burruss, G. W. (2010). The general theory of crime and computer hacking: Low selfcontrol hackers? In T. J. Holt \& B. H. Schell (eds.) Corporate hacking and technology-driven crime: Social dynamics and implications (pp. 38-67). Hershey, PA: IGI Global.

Brown, J. (2008). From Friday to Sunday: The hacker ethic and shifting notions of labour, leisure, and intellectual property. Leisure Studies, 27(4), 395-409.

Bulmer, M. (1982). when is disguise justified? Alternatives to covert participant observation. Qualitative Sociology, 5(4), 251-264. 
Burgess, R. L. \& Akers, R. (1966). A differential association-reinforcement theory of criminal behavior. Social Problems, 14, 128-147.

Burke, R. J., \& Mattis, M. C. (2007). Women and minorities in science, technology, engineering, and mathematics: upping the numbers. Northampton, MA: Edward Elgar Publishing.

Charmaz, K. (2006). Constructing grounded theory: A practical guide through qualitative analysis. Thousand Oaks, CA: Sage Publications, Inc.

Coleman, G. E. (2010). The hacker conference: A ritual condensation and celebration of a lifeworld. Anthropological Quarterly, 83(1), 47-72.

Coleman, G. (2012). Phreakers, hackers, and trolls and the politics of transgression and spectacle. In M. Mandiberg (ed.) The social media reader (pp. 99-119). New York, NY: NYU Press.

Coleman, G. E. (2013). Coding freedom: The ethics and aesthetics of hacking. Princeton, NJ: Princeton University Press.

Coleman, G. E. \& Golub, A. (2008). Hacker practice: Moral genres and the cultural articulation of liberalism. Anthropological Theory, 8(3), 255-277.

Dafermos, G. \& Söderberg, J. (2009). The hacker movement as a continuation of labour struggle. Capital E Class, (97), $53-73$.

Downing, S. (2011). Retro gaming subculture and the social construction of a piracy ethic. International Journal of Cyber Criminology, 5(1), 750-772.

Furnell, S. (2010). Hackers, viruses and malicious software. In Y. Jewkes \& M. Yar (eds.) handbook of internet crime (p. 173-193). Portland, OR: Willan Publishing, Inc.

Glaser, B. G. \& Strauss, A. L. (1967). The discovery of grounded theory: Strategies for qualitative research. Chicago: Aldine Publishing Company.

Halbert, D. (1997). Discourses of danger and the computer hacker. The Information Society. 13(4), 361374.

Higgins, G. E. (2010). Cybercrime: An introduction to an emerging phenomenon. New York, NY: McGraw Hill Higher Education.

Himanen, P. (2001). The hacker ethic: A radical approach to the philosophy of business. New York, NY: Random House, Inc. 
Hollinger, R. (1991). Hackers: Computer heroes or electronic highwaymen? Computers \& Society, 21(1), 617.

Holt, T. J. (2009). Lone hacks or group cracks: Examining the social organization of computer hackers. In F. Schmalleger \& Michael Pittaro (eds.) Crimes of the Internet (pp. 336-355). Upper Saddle River, NJ: Pearson Education, Inc.

Holt, T. J. (2010a). Becoming a computer hacker: Examining the enculturation and development of computer deviants. In P. Cromwell (ed.) In their own words: Criminals on crime: An anthology (5th ed.) (pp. 109-123).

Holt, T. J. (2010b). Examining the role of technology in the formation of deviant subcultures. Social Science Computer Review, 28(4) 466-481.

Holt, T. J., Strumsky, D., Smirnova, O., \& Kilger, M. (2012). Examining the social networks of malware writers and hackers. International Journal of C yber Criminology, 6(1), 891-903.

Jordan, T. \& Taylor, P. (1998). A sociology of hackers. The Sociological Review, 46(4), 757-780.

Kirkpatrick, G. (2002). The hacker ethic and the spirit of the information age. Max Weber Studies, 2 (2), 163-185.

Laub, J. H., \& Sampson, R. J. (1993). Turning points in the life course: Why change matters to the study of crime. Criminology, 31, 301-325.

Leman-Langlois, S. (2013). Technocrime, policing and surveillance. New York, NY: Routledge.

Levy, S. (1984). Hackers: Heroes of the computer revolution. New York, NY: Penguin Group Inc.

Marcum, C. D., Higgins, G. E., Ricketts, M. L., \& Wolfe, S. E. (2014). Hacking in high school: Cybercrime perpetration by juveniles. Deviant Behavior, 35(7), 581-591.

McKenzie, J. (1999). !nt3rh4ckt!v!ty. Style, 33(2), 283-299.

Meikle, G. (2002). Future active: Media activism and the internet. New York, NY: Routledge.

Morris, R. (2010). Computer hacking and techniques of neutralization. In T. J. Holt \& B. H. Schell (eds.) Corporate hacking and technology-driven crime: Social dynamics and implications (pp. 1-17). Hershey, PA: IGI Global.

National Science Foundation. (2013). Women, minorities, and persons with disabilities in science and engineering: 2013 [Special Report NSF 13304]. Arlington, VA: National Science Foundation. 
Nhan, J. \& Huey, L. (2013). 'We don't have these laser beams and stuff like that': Police investigations as low-tech work in a high-tech world. In S. Leman-Langlois (ed.) Technocrime, policing and surveillance (pp. 79-90). New York, NY: Routledge.

Nichols, R., Ryan, D., \& Ryan, J. (2000). Defending your digital assets against hackers, crackers, spies, and thieves. New York, NY: McGraw-Hill.

Obama, B. (2012). Taking the cyberattack threat seriously. The Wall Street Journal (July 19).

Olson, P. (2012). We are Anonymous: Inside the hacker world of LulzSec, Anonymous, and the Global Cyber Insurgency. New York, NY: Little, Brown and Company.

Perez, E., \& Prokupecz, S. (2014, May 19). More than 100 people nabbed in global hacker crackdown. CNN.

Rogers, M., Smoak, N. D., \& Liu, J. (2006). Self-reported deviant computer behavior: A big-5, moral choice, and manipulative exploitive behavior analysis. Deviant Behavior, 27(3), 245-268.

Sampson, R. J. \& Laub, J. H. (1992). Crime and deviance in the life course. Annual Review of Sociology, 18, 63-84.

Schell, B. H., Dodge, J. L., \& Moutsatsos, S. S. (2002). The hacking of America: Who's doing it, why, and how. Westport, CT: quorum Books.

Schell, B. h. \& holt, T. J. (2010). A profile of the demographics, psychological predispositions, and social/behavioral patterns of computer hacker insiders and outsiders. In T. J. Holt \& B. H. Schell (eds.) Corporate hacking and technology-driven crime: Social dynamics and implications (pp. 190-213). Hershey, PA: IGI Global.

Schell, B. H., Melnychuk, J. (2010). Female and male hacker conferences attendees: Their autismspectrum quotient (Aq) scores and selfreported adulthood experiences. In T. J. Holt \& B. H. Schell (eds.) Corporate hacking and technology-driven crime: Social dynamics and implications (pp. 144-168). Hershey, PA: IGI Global.

Skibell, R. (2002). The myth of the computer hacker. Information, Communication \& Society, 5(3), 336356.

Söderberg, J. (2008). hacking capitalism: The free and open source software movement. New York, NY: Routledge.

Steinmetz, K. F. (2014, Online First). Craft(y)ness: An ethnographic study of hacking. British Journal of Criminology. 
Steinmetz, K. F. \& Gerber, J. (2014). “The greatest crime syndicate since the Gambinos”: A hacker critique of government, law, and law enforcement. Deviant Behavior, 35(3), 243-261.

Taylor, P. A. (1999). Hackers: Crime in the digital sublime. New York, NY: Routledge.

Taylor, P. A. (2005). From hackers to hacktivists: Speed bumps on the global superhighway? new Media E Society, 7(5), 625-646.

Thomas, D. (2002). hacker culture. Minneapolis, MN: University of Minnesota Press.

Thomas, J. (2005). The moral ambiguity of social control in cyberspace: A retro-assessment of the 'golden age' of hacking. new Media \& Society, 7(5), 599-624.

Turgeman-Goldschmidt, O. (2005). Hackers' accounts: Hacking as a social entertainment. Social Science Computer Review, 23(1), 8-23.

Turgeman-Goldschmidt, O. (2011). Identity construction among hackers. In K. Jaishankar (ed.) CyberCriminology: Exploring Internet Crimes and Criminal Behavior (pp. 31-51). Boca Raton, FL: CRC Press.

Turkle, S. (1984). The second self: Computers and the human spirit. New York, NY: Simon \& Schuster.

Van Laer, J. \& Van Aelst, P. (2010). Cyber-protest and civil society: the Internet and action repertoires in social movements. In Y. Jewkes \& M. Yar (Eds.) handbook of internet crime (p. 230-254). Portland, OR: Willan Publishing, Inc.

Voiskounsky, A. E. \& Smyslova, O. V. (2003). Flow-based model of computer hackers' motivation. CyberPsychology \& Behavior, 6(2), 171-180.

Wall, D. S. (2007). Cybercrime: The transformation of crime in the information age. Malden, MA: Polity. Wark, M. (2004). A hacker manifesto. Cambridge, MA: Harvard University Press.

Warnick, B. (2004). Technological metaphors and moral education: The hacker ethic and the computational experience. Studies in Philosophy and Education, 23(4), 265-281.

Woo, H., Kim, Y., Dominick, J. (2004). Hackers: Militants or merry pranksters? A content analysis of defaced web pages. Media Psychology, 6(1), 63-82.

Yar, M. (2013). Cybercrime and society (2nd ed.). Thousand Oaks, CA: Sage. 


\section{Contributor}

Kevin F. Steinmetz is an Assistant Professor in the Department of Sociology, Anthropology, and Social Work at Kansas State University. He serves as the book review editor for the Journal of Qualitative Criminal Justice and Criminology. His primary area of study is hacker culture. Other areas of interest also include the intersection between technology and society, criminal justice and popular culture, and inequality issues in criminal justice. His research has appeared in The British Journal of Criminology, Deviant Behavior, Race $\mathcal{E}$ Justice, and Criminal Justice Policy Review, among others.

\section{Acknowledgement}

The author would like to thank Jurg Gerber, Dennis Longmire, and Howard Henderson for their support and insight throughout the research process. Appreciation is also extended to Willard Oliver for providing feedback on an early draft of this manuscript. Finally, a tremendous debt of gratitude is also owed to the hackers of Union Hack who made this research possible.

\section{Footnotes}

1. The term "technocrime", borrowed from Leman-Langlois (2013), is adopted here instead of "cybercrime" to avoid the litany of symbolic and ideological baggage such a term carries. $€$

2. In this study, the term gender is used to note the socially constructed nature of masculinity and femininity. That said, it appears as if Western gender categories and dualistic sex categories correlate perfectly in this study. As such, an argument could be made that sex or gender could be used interchangeably. This study, however, assumes differences in the hacker community are more likely associated with explanations oriented around gender rather than sex and, as such, adopts the former nomenclature. $\triangleq$

3. DEF CON is the largest hacker convention in the world. Starting in 1993, the convention is held annually in Las Vegas and serves as a social epicenter for many in the hacker community. While many participants emphasize security hacking, hackers from all over the hacking continuum participate including hardware hackers, free and open source software programmers, and others. $€$

4. Schell, Dodge, \& Moutsatsos (2002) similarly found income levels and occupational statuses among survey respondents indicating middle class statuses as predominant throughout the hacker community. $\bullet$

5. Holt (2010a) has similarly discussed how hacker development hinges on access to technology. 